\title{
Free-Flow Speed Model Based on Portuguese Roadway Design Features for Two-Lane Highways
}

\author{
António Lobo, Carlos Rodrigues, and António Couto
}

\begin{abstract}
Speed is a key performance measure in economic and environmental analyses of two-lane highways. Speed, combined with the percentage of time spent following, is also used in the assessment of level of service. Under free-flow conditions, the circulation of a given vehicle is not constrained by the presence of other vehicles, and the driver's speed choice reflects the driver's response to the geometric features of the road and roadside interference, as well as the driver's perception of risk. Many studies concerned with the effects of road characteristics, design features in particular, on vehicle speed have been conducted in several countries in recent decades. These studies have provided useful tools for modeling speed and evaluating alignment consistency. This paper presents an exponential free-flow speed model, applicable to both curves and tangents, developed for two-lane highways in Portugal. The variables included in the model are representative not only of the road element under consideration (curve or tangent) but also of the preceding road section and of the visual field downstream from the element. The results from this model are compared with other authors' results and with the guidelines in the Highway Capacity Manual 2010. In addition to the primary influence of the horizontal curvature on speed, the results show that other factors, such as the cross-sectional width, the density of access points, and the downstream visibility, are important.
\end{abstract}

Speed is a major factor in the assessment of road performance. Depending on the functional classification of a given road, a design speed is established, and engineers define the geometric features of the road to ensure that drivers can, in normal traffic conditions, achieve the expected average travel speed to reach their destinations on time. Furthermore, an operating speed may be estimated for performance evaluation during the road operation period. Real environment speed measurements are required, and the operating speed is typically associated with the 85 th percentile of the observed speed distribution (1). Speed is usually recognized by road planners, designers, and users as an important measure for the evaluation of the level of service, speed limit definition, design consistency and safety analyses, and other essential studies.

Recognizing the role of speed in road performance evaluation, the Highway Capacity Manual 2010 (HCM) (2) recommends speed as the most appropriate concept for use in the economic

Department of Civil Engineering, Transport Infrastructure Division, University of Porto, Rua Dr. Roberto Frias, s/n, 4200-465 Porto, Portugal. Corresponding author: A. Lobo, lobo@fe.up.pt.

Transportation Research Record: Journal of the Transportation Research Board, No. 2348, Transportation Research Board of the National Academies, Washington,

D.C., 2013, pp. 12-18.

DOI: $10.3141 / 2348-02$ and environmental analyses of two-lane highways, including the assessment of the impact on air quality and noise level. In addition, the HCM methodology to assess the level of service of this type of road also uses the average travel speed as an input, which in turn depends on the free-flow speed (FFS) and on the traffic volume. In other words, the average travel speed adds the effects of the delays caused by the remaining traffic to the FFS. The FFS reflects the drivers' response to the road's geometric and environmental features because drivers are not affected by the presence of other vehicles. The definition of the FFS proposed by the HCM is similar to the definition of operating speed given by the AASHTO Green Book (1). However, operating speed may also be affected by drivers' perception of risk, speed limit and enforcement, general driving practices and culture, and vehicle technology. For this reason, speed prediction models have been developed in different regions worldwide and in different time periods.

Reference manuals and national guides for road design usually define operating speed for a road section rather than for specific design elements. The HCM (2) establishes a base FFS as the speed observed for roads presenting no access points and lane and shoulder widths equal to or greater than $3.6 \mathrm{~m}$ and $1.8 \mathrm{~m}$, respectively. The HCM also provides an FFS estimation model, taking into account speed reductions to the base FFS caused by smaller cross sections and higher densities of access points.

The AASHTO Green Book (1) also provides recommendations for design and operating speeds. Different design speeds are suggested according to the functional classification intended for a planned road, and speed differences between adjacent road sections are recommended to avoid excessive values of acceleration or deceleration. In brief, the guidelines for road design proposed by this manual consist of an effort to provide efficient infrastructures, capable of dealing with the expected operating speeds and travel times and of ensuring the required safety standards along the road's entire length.

Similar criteria are proposed by the Portuguese guidelines for road design (3). In other countries, official approaches suggest operating speeds based on the curvature change rate and pavement width, in the case of Germany (4), and on the amount of bend or curvature and mean visibility, in the case of the United Kingdom (5).

Many authors have also been working on modeling speed using an academic approach. A microscopic perspective has been commonly adopted by the researchers who have been exploring a comprehensive range of factors with potential impacts on speed, resulting in several speed models for different geometric features, types of vehicles, and environmental conditions. Some useful tools for a thorough design consistency evaluation have been provided by these studies (6-9). 
The horizontal alignment has usually been regarded as the most important factor affecting speed, and its curvature may be characterized by different indicators, such as the radius, the degree of curve, the curvature change rate, and the deflection angle. Several models consider these features as the only ones exerting significant impacts on speed, such as the work by Morrall and Talarico (10), Passetti and Fambro (11), Misaghi and Hassan (12), and Kanellaidis et al. (13).

The influence of the vertical alignment on speed has been less studied than the effects of the horizontal alignment, perhaps because of its smaller importance to the circulation of passenger cars. Nevertheless, some relevant research on this field has been conducted to account for the simultaneous effect of the horizontal and vertical alignments on driving behavior. The research conducted by Fitzpatrick et al. (14) and Gibreel et al. (15) proposed speed models categorized by vertical alignment conditions. Donnell et al. (10) modeled the speed of trucks in horizontal curves; they took into account the grades of the approach and departure tangents.

The effects of the cross-sectional width have also been studied by several authors. Lamm and Choueiri (7) used the lane and shoulder widths as inputs for a speed model developed for the state of New York. Lamm et al. (8) proposed speed models categorized by lane widths. Melo et al. (17) conducted a driving simulator study to estimate speed reductions produced by different lane and shoulder widths; they compared the results with the HCM guidelines (2).

The influence of the driver's expectations about the road alignment has been introduced in spot speed models through the use of variables to characterize the upstream and downstream road sections. In this sense, the speed on the approach tangent, used by Krammes et al. (6) and Bonneson et al. (18), and the concept of desired speed of the road section proposed by McLean (19) were included in the curve speed models developed by these authors. The downstream features considered in the literature are mainly related to the driver's field of vision $(5,20)$.

Other variables have been considered in speed modeling, such as the curve or tangent extension $(6,21-23)$, the superelevation rate $(15,18,21)$, and the posted speed limit $(8,22)$.

Although numerous speed models have been proposed by the research community, public authorities, and road operators, the model presented in this paper is distinctive in two ways: $(a)$ it allows for the FFS estimation for a given curve or tangent, taking into account not only the characteristics of the element but also the effects of upstream and downstream road sections, and $(b)$ it uses an exponential regression approach for the FFS modeling instead of the commonly used linear form. These two features address concerns raised in Transportation Research Circular E-C151 (24), namely, the relatively few tangent speed models and the limitations of linear regression.

The proposed FFS model is applied to Portuguese two-lane highways, and because it can be applied to curves and tangents, it may also be used as a design consistency evaluation tool, providing an alternative to the procedure in the Portuguese guide for road design (3).

\section{DESCRIPTION OF MODEL}

The model estimates the FFS at a given horizontal element of the road (curve or tangent) through an exponential function of the road features, as shown in Equation 1:

$$
\begin{aligned}
\mathrm{FFS}= & f\left(X_{\text {ele }}, X_{\text {up }}, X_{\text {down }}\right)=\beta_{0} \cdot \exp \left(\beta_{1} X_{\text {ele }}\right) \cdot \exp \left(\beta_{2} X_{\text {up }}\right) \\
& \cdot \exp \left(\beta_{3} X_{\text {down }}\right)
\end{aligned}
$$

where

$$
\begin{aligned}
X_{\text {ele }} & =\text { features of road element, } \\
X_{\text {up }} & =\text { features of upstream road section, } \\
X_{\text {down }} & =\text { features of downstream road section, and }
\end{aligned}
$$

$\beta_{0}, \beta_{1}, \beta_{2}, \beta_{3}=$ regression coefficients.

An advantage of the exponential equation is the interaction between the effects of road features and the order of magnitude of the practiced speeds. In the linear form of the FFS calculation, however, independent variables produce cumulative impacts on speed that are independent from the road type. Thus, the adoption of an exponential function seems to be more appropriate for speed modeling for European countries, where operating speeds on two-lane highways differ significantly, resulting in changing the effects of road geometrics.

The three sets of variables $X_{\text {ele }}, X_{\text {up }}$, and $X_{\text {down }}$ represent the road geometric features and roadside interference that affect drivers' speed choice. $X_{\text {ele }}$ characterizes the curve or tangent in which the FFS is being estimated and may encompass factors such as the horizontal radius, length, grade, lane width, and shoulder width. $X_{\text {up }}$ describes the upstream road section that may affect the FFS and includes factors such as the density of intersections and roadside buildings. The upstream road section to be considered may vary in length depending on the local conditions. $X_{\text {down }}$ represents the downstream road features that may affect driving behavior and is typically influenced by the sight distance. In summary, the model proposed in Equation 1 expresses the idea that a driver's behavior on a given tangent or curve depends not only on the characteristics of that element but also on the recent driving experience and on the road features that the driver can observe downstream. This assumption has been explored by other authors, although they have used different approaches.

\section{APPLICATION OF MODEL}

\section{Data Description}

In the test of the FFS model on Portuguese roadways, the case study road sections were chosen from five roads in northern Portugal: $\mathrm{N} 14$, N 101, N105-2, N 206, and N 222. These road sections are located outside urban areas, and the marginal land use varies from the complete absence of construction to the existence of some isolated buildings, as shown in Figure 1. The posted speed limits are 50, 70, or $90 \mathrm{~km} / \mathrm{h}$, and the terrain type is consistent with the classification of rolling terrain (2).

Spot speed data were collected from 61 curves and 27 tangents over the $116 \mathrm{~km}$ of road. Because the model uses both upstream and downstream road features, speed must be measured separately for each direction, doubling the number of observations (176 observations).

Speed measurements were performed during the day in clear weather conditions. The pavement of the selected sections was in good shape, without cracks or potholes (which may cause speed reductions) and with clearly visible markings. Vehicle speeds were recorded with traffic counting devices, a Doppler radar sensor with an integrated Flash RAM data memory, and a real-time clock, which were placed at the approximate midpoint of the selected tangents and curves. Because drivers tend to brake in the presence of unfamiliar objects installed at the roadside, when possible, the equipment was fixed at a height of approximately $2.5 \mathrm{~m}$ using public lighting poles. When this installation was not possible, other steps were taken to disguise the traffic counters. 


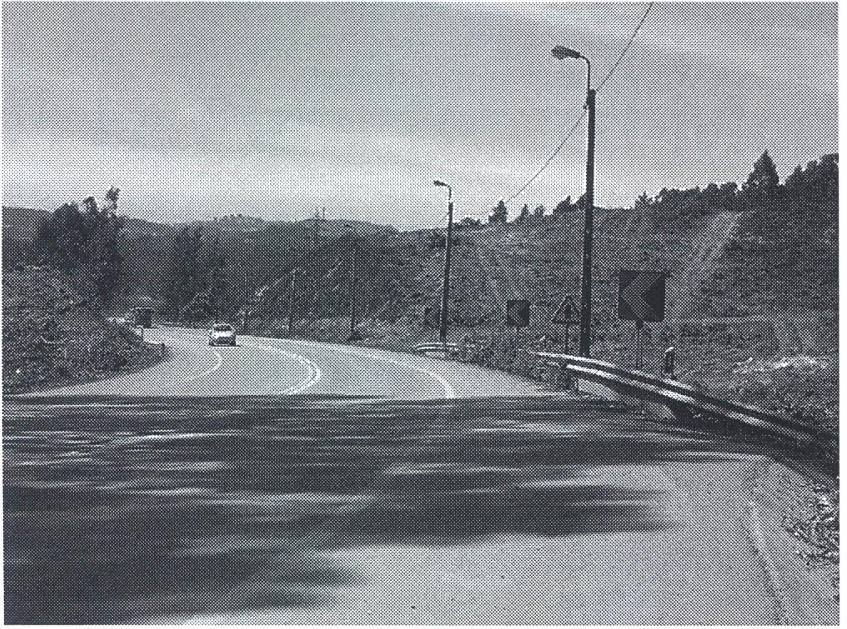

(a)

FIGURE 1 Examples of road sections considered for case studies.

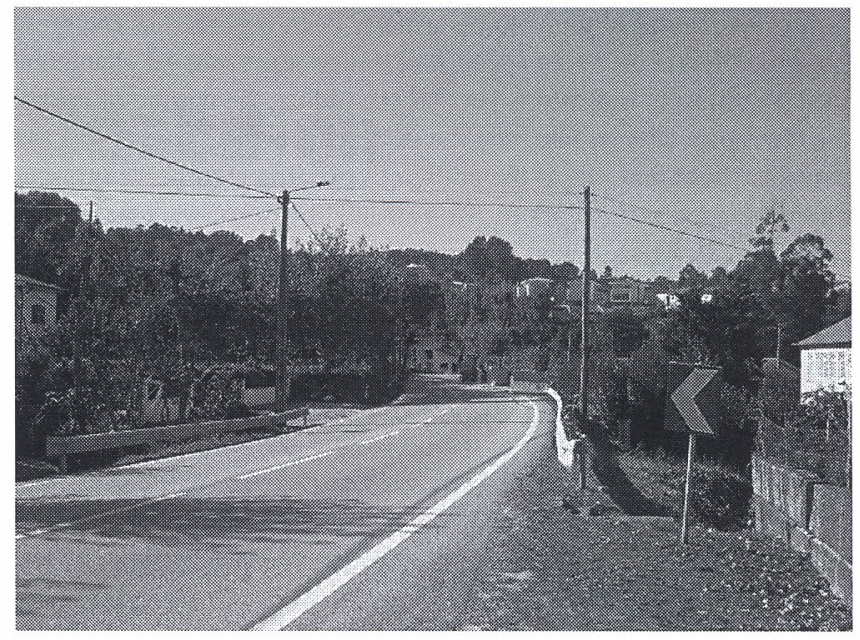

(b)
The FFS associated with a particular road element is the 85 th percentile of the speed distribution of unconstrained vehicles (V85). It is assumed that free-flow traveling is established between vehicles that are separated by at least $6 \mathrm{~s}$, as proposed by Lobo et al. (25) in a study conducted on Portuguese two-lane highways. The spot speeds of more than 90,000 free-flow vehicles were measured at the selected sites, ensuring a minimum of 100 registers per direction for each site, as recommended by the HCM for V85 estimation (2). The percentage of heavy vehicles traveling in the case study roads is estimated in around $10 \%$ of the total number of vehicles.

The road geometry and roadside interference data were collected with an onboard Global Positioning System device and a digital video recording system installed in the instrumented vehicle of the Traffic Analysis Laboratory of the Faculty of Engineering of the University of Porto. Besides the vehicle speeds, the collected variables were

- Features of the road horizontal element (i.e., dummy variable for curves, curve radius, length, grade, one-direction pavement width, and extra lateral clearance),

- Features of the upstream road section (i.e., amount of bend or curvature, density of intersections, and density of roadside buildings), and

- Feature of the downstream road section (i.e., dummy variable for constrained visibility).

In the FFS model, to account for curves or tangents using the same mathematical expression, the dummy variable for curves is set to 1 for a curved section and to 0 for a tangent section. The curve radius is eliminated for the tangent section by multiplication by the dummy variable. Representative average values for the sites were used for the grade and the cross-sectional variables. The pavement width (in one direction) is given by the sum of the lane and shoulder widths, and the extra lateral clearance is the distance between the shoulder external limit and any fixed object at the roadside.

In the Portuguese case study, the FFS for a given curve or tangent includes effects from the 1-km upstream road section. The amount of bend or curvature is represented by the total deflection angle of the horizontal alignment per kilometer, and the densities of roadside buildings and intersections correspond to the number of marginal constructions per kilometer and the number of intersections with other public roads per kilometer, respectively. Because reliable vertical alignment data could not be collected through the Global Positioning System data collection system, this feature was not included. The authors believe that the upstream vertical alignment does not affect the FFS significantly, as compared with the upstream horizontal alignment, which influences drivers' expectations of the road's safety standards.

A single dummy variable representing the driver's visibility is used to characterize the effects of the downstream road section on the FFS. This variable implies that the downstream section affects the driver's choice of speed only through the geometric features that the driver is able to see at the moment. The dummy variable is equal to 1 if the driver is driving on a curve with a radius equal to or smaller than the absolute minimum radius or if there is such a curve within the decision sight distance; the variable is equal to 0 otherwise. The absolute minimum radius and the decision sight distance depend on the operating speed and are defined in the Portuguese guide for road design (3).

The statistics of the variables included in the model for the test sites are shown in Table 1.

\section{Regression Modeling}

A multiple exponential regression using a linearized form of Equation 1 was used to model the FFS for Portuguese two-lane highways. The regression coefficients and standard errors are shown in Table 2. With the exception of the dummy variables, these coefficients represent the elasticities of the road features.

The correlation coefficient $(R)$ above 0.50 achieved by the exponential model represents large correlations between the dependent and the independent variables (26). For comparison, a linear regression was also applied to the data, resulting in a lower coefficient of determination $\left(R^{2}\right)$. The residuals are normally distributed, as confirmed by the Kolmogorov-Smirnov test, resulting in a $p$-value of 0.49 .

The results presented in Table 2 show that traveling in a curved section is the most important factor that affects speed choice, and the factor may negatively affect the FFS about $47 \%$. Such behavior was expected because curves with relatively large radii are uncommon in Portuguese two-lane highways, and the test case road sections are not exceptions. The decrease in $10 \%$ of the curve radius produces a FFS reduction of about $1.2 \%$. The length of the element presents a 
TABLE 1 General Data on Curves and Tangents

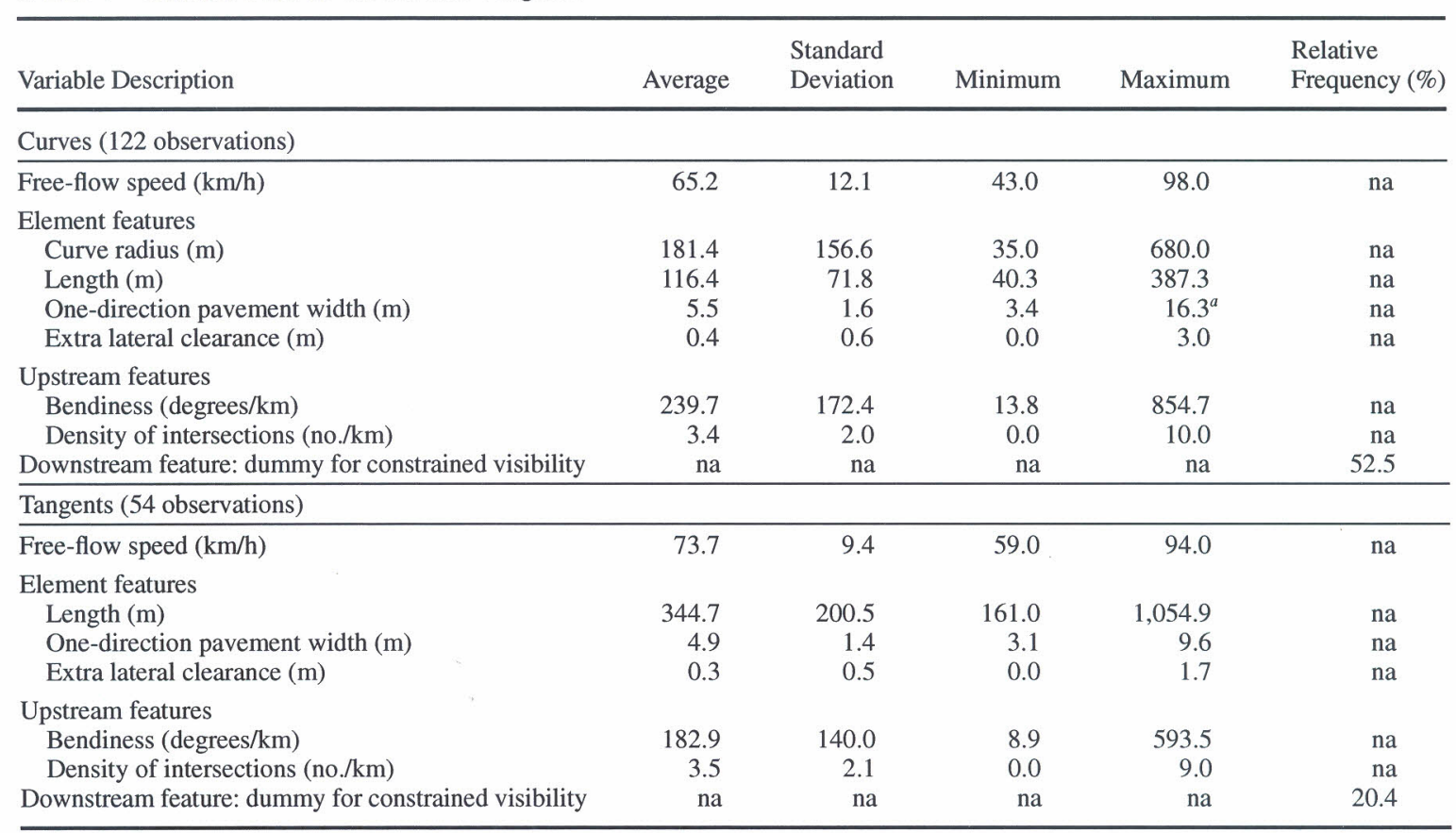

Note: na = not applicable; no. $=$ number.

${ }^{a}$ This exceptional value corresponds to one site featuring an unmarked parking area at the roadside.

positive elasticity $(0.065)$, which is similar to the combined effects of the cross-section variables $(0.067)$.

Harsher geometric features and roadside interference of the adjacent sections reduce the FFS at a given curve or tangent, although they produce smaller effects than the specific conditions at the road element. The increase in $10 \%$ of both upstream features-amount of bend or curvature and density of intersections - causes a decrease in the FFS of about $0.6 \%$, and the downstream constrained visibility may reduce the FFS about $4 \%$.

Two of the collected variables, grade and density of roadside buildings, were not statistically significant at the $10 \%$ level and were subsequently removed from the model. In this case study, the density of roadside buildings shows multicollinearity with the density of inter-

\section{TABLE 2 Results of Multiple Exponential Regression}

\begin{tabular}{lcc}
\hline Variable & Coefficient & Standard Error \\
\hline Constant & 3.999 & $0.132^{a}$ \\
Element features & & \\
$\quad$ Dummy for curve & -0.626 & $0.093^{a}$ \\
$\quad$ Curve radius & 0.118 & $0.017^{a}$ \\
$\quad$ Length & 0.065 & $0.019^{a}$ \\
$\quad$ One-direction pavement width & 0.058 & $0.035^{b}$ \\
$\quad$ Extra lateral clearance & 0.009 & $0.004^{a}$ \\
Upstream features & & \\
$\quad$ Bendiness & -0.019 & $0.011^{b}$ \\
$\quad$ Density of intersections & -0.036 & $0.014^{a}$ \\
Downstream feature: dummy for & -0.043 & $0.023^{b}$ \\
$\quad$ constrained visibility & & \\
\hline
\end{tabular}

NoTE: Residuals: sum of squares $=1.96$; standard error $=0.11$; fit: $R=0.81$ adjusted $R^{2}=0.63 ; \log$ likelihood $=145.95$; autocorrelation: Durbin-Watson statistic $=1.29 ;$ rho $=0.36$.

${ }^{a}$ Significant at the $5 \%$ level.

${ }^{b}$ Significant at the $10 \%$ level. sections because the increase in the number of access points is highly correlated with the crossing of small villages. The lack of significance of the grade may be related to the relatively small grades observed at the speed test sites, with absolute values rarely exceeding $5 \%$ and with an average value of $3 \%$. Therefore, the proposed FFS model is not recommended for mountainous terrain conditions.

The FFS model proposed for Portuguese two-lane highways is shown in Equation 2:

$$
\begin{aligned}
\mathrm{FFS}= & \exp [3.999-0.626 C+0.118 \ln (R) \cdot C+0.065 \ln (L) \\
& +0.058 \ln (\mathrm{PW})+0.009 \ln (\mathrm{ELC})-0.019 \ln (B) \\
& -0.036 \ln (\mathrm{DI})-0.043 \mathrm{CV}]
\end{aligned}
$$

where

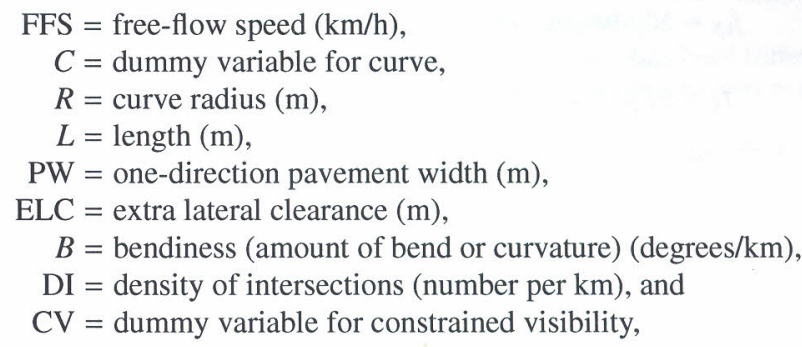
and

ELC, $B$, DI $>0$.

\section{COMPARISON WITH EXISTING SPEED MODELS}

In this section, the results of the proposed FFS model are compared with other speed models proposed by different authors, as well as with the HCM methodology for FFS estimation on two-lane highways (2). 
TABLE 3 Evaluation of Radius Elasticity for Existing Speed Models

\begin{tabular}{lllc}
\hline Author & Location & Speed Model $^{a}$ & Radius Elasticity $^{\circ}$ \\
\hline Morrall and Talarico (10) & Alberta, Canada & $V 85=\exp (4.561-0.00586 \mathrm{DC})$ & 0.094 \\
Passetti and Fambro (11) & New York, Pennsylvania, Oregon, & $V 85=103.9-3,020.5 / R$ & 0.102 \\
& $\quad$ Washington, Minnesota, & & \\
& $\quad$ and Texas & $V 85=91.85+0.00981 R$ & 0.022 \\
Misaghi and Hassan (12) & Ontario, Canada & $V 85=129.88-623.1 / \sqrt{ } R$ & 0.165 \\
Kanellaidis et al. (13) & Greece & &
\end{tabular}

${ }^{a}$ Where $V 85=$ free-flow speed $(\mathrm{km} / \mathrm{h})$, and DC $=$ degree of curve $($ degrees $/ 100 \mathrm{~m}$ of $\operatorname{arc})=5,729.58 / R$.

The horizontal design features are recognized as the main factors affecting the operating speed, and their effects have been widely studied and reported in the literature. Therefore, the influence of the curve radius on the FFS is, among the variables included in this study, the most reliable term of comparison with the existing speed models.

Because these models usually represent linear functions of the radius $(R)$, curvature $(1 / R)$, degree of curve, or other related variables, direct comparisons between coefficients and elasticities are not possible. Thus, the radius elasticities were estimated for a set of selected models. First, the models from the literature were applied to the case study to estimate the FFS for the sample mean. Then, the radius elasticity was calculated by evaluating the impact on the FFS of a $100 \%$ increase in its mean value, with the other variables remaining constant. The results are presented in Table 3.

The radius elasticity of 0.118 obtained for Portuguese conditions is aligned with other model results, and the relatively small differences between these figures may be related to the specific local conditions and driving culture of each region.

From another perspective, the HCM (2) proposes the following FFS estimation model:

$$
\mathrm{FFS}=\mathrm{BFFS}-f_{\mathrm{LS}}-f_{\mathrm{A}}
$$

where

$$
\begin{aligned}
\text { BFFS }= & \text { base free-flow speed }(\mathrm{km} / \mathrm{h}), \\
f_{\mathrm{LS}}= & \text { adjustment parameter for lane and shoulder width }(\mathrm{km} / \mathrm{h}), \\
& \text { and } \\
f_{A}= & \text { adjustment parameter for density of access points }(\mathrm{km} / \mathrm{h}) .
\end{aligned}
$$

It is recommended that Equation 3 be used to estimate the FFS when speed measurements are not possible. In the HCM model, two correction values, $f_{A}$ and $f_{\mathrm{LS}}$, representing road geometric features, are applied to a BFFS, which is the speed observed for roads with (a) no access points and $(b)$ lane and shoulder widths equal to or greater than $3.6 \mathrm{~m}$ and $1.8 \mathrm{~m}$, respectively. The correction values result in reductions to the FFS because of higher densities of access points and smaller cross-section widths.

The HCM methodology is applicable to road sections instead of specific design features (tangents or curves), as is the case of the model presented in this paper. However, because the latter model also encompasses the effects of access point density and of crosssection width, only the sites collected in tangent were considered for the comparison with the HCM model. Otherwise, the results could be strongly affected by the local horizontal curvature. Speed reductions for the same categories of access point density used in the HCM were estimated through the proposed FFS model, using the base cross-section width of a 3.6-m-wide lane combined with a $1.8-\mathrm{m}$-wide shoulder and the sample mean values of the remaining variables. Similarly, speed reductions for the same cross-section features considered in the HCM were evaluated through the proposed FFS model with no access points and the sample mean values of the remaining variables. The results are presented in Table $4\left(f_{A}\right)$ and in Table $5\left(f_{\mathrm{LS}}\right)$.

The proposed FFS model returns values for $f_{A}$ that are similar to the results for the HCM model for the lower categories of access point density. However, unlike the linear behavior assumed by the $\mathrm{HCM}$, estimated speed reductions tend to stabilize as the access point density increases.

With respect to the $f_{\mathrm{LS}}$ values, the results of the proposed FFS model differ significantly from those of the HCM model. First, the inclusion in the model of a wider range of geometric features affecting the FFS leads to an expected reduction in the individual effects of each independent variable. Second, because an exponential function was used, the effects of the road features on the FFS are not cumulative; they depend on the order of magnitude of the speeds practiced on the roads under consideration. In European countries such as Portugal, driving speeds may be considerably different from one road to another and lower than the speeds practiced on most North American two-lane highways. Thus, for the same cross-sectional characteristics, smaller values of $f_{\mathrm{LS}}$ may be observed in Europe.

\section{CONCLUSIONS}

Speed has been a major concern for researchers in road operations and design, and these researchers have developed numerous operating speed models that are applicable in different regions worldwide.

TABLE 4 Reduction in FFS from Access Point Density

\begin{tabular}{lcc}
\hline $\begin{array}{l}\text { Access Points } \\
\text { per Kilometer }\end{array}$ & $\begin{array}{l}\text { HCM 2010 } \\
(\mathrm{km} / \mathrm{h})\end{array}$ & $\begin{array}{l}\text { Proposed Model } \\
(\mathrm{km} / \mathrm{h})\end{array}$ \\
\hline 0 & 0.0 & 0.0 \\
6 & 4.0 & 4.9 \\
13 & 8.0 & 6.9 \\
19 & 12.0 & 7.9 \\
25 & 16.0 & 8.6 \\
\hline
\end{tabular}


TABLE 5 Reduction in FFS from Cross-Section Width

\begin{tabular}{|c|c|c|c|c|c|c|c|c|c|}
\hline \multirow{2}{*}{$\begin{array}{l}\text { Lane Width } \\
\text { (m) }\end{array}$} & \multicolumn{4}{|c|}{$\begin{array}{l}\text { Reduction in FFS }(\mathrm{km} / \mathrm{h}) \\
\text { by Shoulder Width }\end{array}$} & \multirow{2}{*}{$\begin{array}{l}\text { Lane Width } \\
\text { (m) }\end{array}$} & \multicolumn{4}{|c|}{$\begin{array}{l}\text { Reduction in FFS }(\mathrm{km} / \mathrm{h}) \\
\text { by Shoulder Width }\end{array}$} \\
\hline & $0.0 \mathrm{~m}$ & $0.6 \mathrm{~m}$ & $1.2 \mathrm{~m}$ & $1.8 \mathrm{~m}$ & & $0.0 \mathrm{~m}$ & $0.6 \mathrm{~m}$ & $1.2 \mathrm{~m}$ & $1.8 \mathrm{~m}$ \\
\hline \multicolumn{5}{|l|}{ HCM 2010} & \multicolumn{5}{|c|}{ Proposed Model } \\
\hline 2.7 & 10.3 & 7.7 & 5.6 & 3.5 & 2.7 & 3.1 & 2.2 & 1.5 & 0.8 \\
\hline 3.0 & 8.5 & 5.9 & 3.8 & 1.7 & 3.0 & 2.6 & 1.8 & 1.1 & 0.5 \\
\hline 3.3 & 7.5 & 4.9 & 2.8 & 0.7 & 3.3 & 2.2 & 1.5 & 0.8 & 0.3 \\
\hline 3.6 & 6.8 & 4.2 & 2.1 & 0.0 & 3.6 & 1.8 & 1.1 & 0.5 & 0.0 \\
\hline
\end{tabular}

This paper presents the development and testing of a new model to estimate FFS based on the relationship between speed and road geometric features for Portuguese two-lane highways, on which little research has been conducted.

The new model presents two main features that are unusual among the existing models: $(a)$ it takes into account the effects on the FFS produced by the geometries of the sections upstream and downstream from the element under consideration and $(b)$ it uses an exponential function that assumes that the magnitude of the geometric effects is dependent on the order of magnitude of the speeds practiced at a given location. Furthermore, as the model is applicable both to curves and tangents, it may constitute an alternative procedure for design consistency evaluation to that established by the Portuguese guidelines (3).

The results of the modeling application to the Portuguese case study confirmed the primary influence of the horizontal curvature on the operating speed, followed by the secondary influences of element extension and cross-sectional characteristics. The amount of bend or curvature and the roadside interference of the upstream section as well as the downstream constrained visibility also had a significant impact on the FFS, although smaller than the geometric effects of the element.

The influence on the FFS produced by some of the variables considered in this model may vary from the findings of other studies, especially those that were developed for different conditions of road design standards and driving culture, as is the case of the HCM (2). The authors recommend caution when applying the proposed model outside Europe. However, the development of new speed models for non-European conditions that present a similar structure to this model would likely improve speed prediction capabilities.

Additional research on FFS modeling for sections of Portuguese two-lane highways will be conducted in the future.

\section{ACKNOWLEDGMENT}

This study was conducted through the SAFESPEED project, financed by the Portuguese Science and Technology Foundation.

\section{REFERENCES}

1. A Policy on Geometric Design of Highways and Streets, 6th ed. AASHTO, Washington, D.C., 2011.

2. Highway Capacity Manual 2010. Transportation Research Board of the National Academies, Washington, D.C., 2010.
3. Norma de Traçado. Junta Autónoma de Estradas, Almada, Portugal, 1994.

4. RAS-L. Richtlinien fuer die Anlage von Strassen, Teil: Linienfuehrung. Forschungsgesellschaft fuer Strassen-und Verkehrswesen, Cologne, Germany, 1995.

5. The Highways Agency. Geometric Design Is the Design Manual for Roads and Bridges, Vol. 6: Road Geometry, Section 1: Links. London, 2002.

6. Krammes, R. A., Q. Brackett, M. A. Shafer, J. L. Ottesen, I. B. Anderson, K. L. Fink, K. M. Collins, O. J. Pendleton, and C. J. Messer. Horizontal Alignment Design Consistency for Rural Two-Lane Highways. Publication FHWA-RD-94-034. FHWA, U.S. Department of Transportation, 1995.

7. Lamm, R., and E. M. Choueiri. Recommendations for Evaluating Horizontal Design Consistency Based on Investigations in the State of New York. In Transportation Research Record 1122, TRB, National Research Council, Washington, D.C., 1987, pp. 68-78.

8. Lamm, R., E. M. Choueiri, J. C. Hayward, and A. Paluri. Possible Design Procedure to Promote Design Consistency in Highway Geometric Design on Two-Lane Rural Roads. In Transportation Research Record 1195, TRB, National Research Council, Washington, D.C., 1988, pp. 111-122.

9. Gibreel, G. M., S. M. Easa, Y. Hassan, and I. A. El-Dimeery. State of the Art of Highway Geometric Design Consistency. Journal of Transportation Engineering, Vol. 125, 1999, pp. 305-313.

10. Morrall, J. F., and R. J. Talarico. Side Friction Demanded and Margins of Safety on Horizontal Curves. In Transportation Research Record 1435, TRB, National Research Council, Washington, D.C., 1994, pp. $145-152$.

11. Passetti, K. A., and D. B. Fambro. Operating Speeds on Curves With and Without Spiral Transitions. In Transportation Research Record: Journal of the Transportation Research Board, No. 1658, TRB, National Research Council, Washington, D.C., 1999, pp. 9-16.

12. Misaghi, P., and Y. Hassan. Modeling Operating Speed and Speed Differential on Two-Lane Rural Roads. Journal of Transportation Engineering, Vol. 131, 2005, pp. 408-417.

13. Kanellaidis, G., J. Golias, and S. Efstathiadis. Driver's Speed Behavior on Rural Road Curves. Traffic Engineering and Control, Vol. 31, 1990, pp. 414-415.

14. Fitzpatrick, K., L. Elefteriadou, D. W. Harwood, J. M. Collins, J. McFadden, I. B. Anderson, R. A. Krammes, N. Irizarry, K. D. Parma, K. M. Bauer, and K. Passetti. Speed Prediction for Two-Lane Rural Highways. Publication FHWA-RD-99-171. FHWA, U.S. Department of Transportation, 2000.

15. Gibreel, G. M., S. M. Easa, and I. A. El-Dimeery. Prediction of Operating Speed on Three-Dimensional Highway Alignments. Journal of Transportation Engineering, Vol. 127, 2001, pp. 21-30.

16. Donnell, E. T., Y. Ni, M. Adolini, and L. Elefteriadou. Speed Prediction Models for Trucks on Two-Lane Rural Highways. In Transportation Research Record: Journal of the Transportation Research Board, No. 1751, TRB, National Research Council, Washington, D.C., 2001, pp. 44-55.

17. Melo, P., A. Lobo, A. Couto, and C. M. Rodrigues. Road CrossSection Width and Free-Flow Speed on Two-Lane Rural Highways. 
In Transportation Research Record: Journal of the Transportation Research Board, No. 2301, Transportation Research Board of the National Academies, Washington, D.C., 2012, pp. 28-35.

18. Bonneson, J., M. Pratt, J. Miles, and P. Carlson. Development of Guidelines for Establishing Effective Curve Advisory Speeds. Texas Transportation Institute Research Report 05439-1. Texas A\&M University System, College Station, 2007.

19. McLean, J. Driver Speed Behaviour and Rural Road Alignment Design. Traffic Engineering and Control, Vol. 22, 1981, pp. 208-211.

20. Andueza, P. J. Mathematical Models of Vehicular Speed on Mountain Roads. In Transportation Research Record: Journal of the Transportation Research Board, No. 1701, TRB, National Research Council, Washington, D.C., 2000, pp. 104-110.

21. Voigt, A. P., and R. A. Krammes. An Operational and Safety Evaluation of Alternative Horizontal Curve Design Approaches on Rural Two-Lane Highways. Texas Transportation Institute Research Report 04690-3. Texas A\&M University System, College Station, 1996.

22. Schurr, K. S., P. T. McCoy, G. Pesti, and R. Huff. Relationship of Design, Operating, and Posted Speeds on Horizontal Curves of Rural Two-Lane Highways in Nebraska. In Transportation Research Record:
Journal of the Transportation Research Board, No. 1796, Transportation Research Board of the National Academies, Washington, D.C., 2002, pp. 60-71.

23. Cardoso, J., A. L. Macedo, G. Kanellaidis, A. Flouda, I. Dimitropoulos, H. Peltola, S. Ranta, and G. Dupré. Improvement of Models on the Relations Between Speed and Road Characteristics. SAFESTAR Task 5.3 Report. Laboratório Nacional de Engenharia Civil, Lisbon, Portugal, 1998.

24. Transportation Research Circular E-C151: Modeling Operating Speed: Synthesis Report. Transportation Research Board of the National Academies, Washington, D.C., 2011.

25. Lobo, A., M. A. P. Jacques, C. M. Rodrigues, and A. Couto. Free-Gap Evaluation for Two-Lane Rural Highways. In Transportation Research Record: Journal of the Transportation Research Board, No. 2223, Transportation Research Board of the National Academies, Washington, D.C., 2011, pp. 9-17.

26. Cohen, J. Statistical Power Analysis for the Behavioral Sciences, 2nd ed. Lawrence Erlbaum Associates Inc., Hillsdale, N.J., 1988.

The Operational Effects of Geometrics Committee peer-reviewed this paper. 